\title{
A DESIGUALDADE DA SELEÇÃO CRIMINALIZANTE SECUNDÁRIA EM RELAÇÃO DE EXCEÇÃO: REFLEXÕES A PARTIR DE GIORGIO AGAMBEN
}

\author{
Luanna Tomaz de Souza* \\ Antonio José Martins Fernandes***
}

\section{Resumo:}

O presente trabalho tem o objetivo de responder à pergunta: de que forma o pensamento de Giorgio Agamben se perfaz através do processo de seleção criminalizante secundária. A pergunta surge a partir da percepção das desigualdades reproduzidas por estes processos, conforme observou pelas estatísticas criminais. Compara-se esse contexto com os elementos essenciais do pensamento de Agamben. Utiliza-se a metodologia de levantamento bibliográfico e documental para análise comparativa dos elementos com a realidade da seleção criminalizante realizada pelas agências policiais no Brasil, concluindo que, apesar das diferenças entre os contextos, estes podem ser materiais de interpretação e compreensão da nossa realidade.

Palavras-Chave: Processo de criminalização. Seletividade. Relação de exceção. Vida nua. Racismo

\section{THE INEQUALITY OF SECONDARY CRIMINALIZATION SELECTION IN RELATION TO EXCEPTION: REFLECTIONS FROM GIORGIO AGAMBEN}

\begin{abstract}
:
The present work aims to answer the question: how Giorgio Agamben's thinking is achieved through the secondary criminalizing selection process. The question arises from the perception of the inequalities reproduced by these processes, as noted by criminal statistics. This context is compared with the essential elements of Agamben's thought. The bibliographic and documentary survey methodology is used for comparative analysis of the elements with the reality of the criminalizing selection carried out by the police agencies in Brazil, concluding that, despite the differences between the contexts, these can be materials of interpretation and understanding of our reality.
\end{abstract}

Key words: Criminalization process. Selectivity. Exception relation. Naked life. Racism

\section{Considerações iniciais}

\footnotetext{
* Advogada. Pós-doutora em Direito (PUC-RIO). Doutora em Direito (Universidade de Coimbra). Professora da Graduação e da Pós-graduação em Direito da Universidade Federal do Pará (UFPA). Email: luannatomaz@ufpa.br. End: Lomas Valentina, 991. Ap: 804, Pedreira, CEP: 66087-441, Belém-Pa.

Advogado. Mestrando pelo Programa de Pós-graduação em Direito da Universidade Federal do Pará (UFPA), sob orientação da prof ${ }^{a}$ Luanna Tomaz de Souza. Pós-graduando em Ciências Criminais do Programa de Pósgraduação do Centro Universitário do Pará (CESUPA). E-mail: ajmf06@gmail.com. End. postal: Rua Tiradentes, $\mathrm{n}^{\circ}$ 175, bairro do Reduto, CEP 66053-330, Belém-PA.
} 
O presente artigo tem a finalidade de apresentar as características do sistema penal e da atuação das agências policiais na figura da polícia militar e as relacionar com os pensamentos do filósofo italiano Giorgio Agamben acerca da relação de exceção, do soberano do homo sacer.

O trabalho tem a finalidade de responder a pergunta: de que forma o pensamento agambeniano se perfaz através do processo desigual de seleção criminalizante secundária? A partir disso, o objetivo geral é demonstrar a presença dos elementos da filosofia de Agamben no processo seletivo realizado pelas agências policiais brasileiras. Como objetivos específicos, pretende-se abordar as características do processo de seleção criminalizante secundária e as características das categorias que mais comumente o compõem como raça, classe social e território e também explorar os elementos basilares do pensamento agambeniano e os relacionar com o sistema penal brasileiro.

Para fundamentar as reflexões e conclusões do artigo, o referencial teórico adotado será o da criminologia crítica, uma vez que este adota o entendimento de que a criminalidade não é um fenômeno ontológico, mas sim fruto de atribuições (desiguais) da característica da criminalidade através dos processos de criminalização (BARATTA, 2011, p. 161).

A metodologia utilizada é de levantamento bibliográfico acerca de autores da criminologia crítica, da sociologia e da filosofia sobre os pensamentos agambenianos, sobre o processo de criminalização secundária e das categorias que compõem esse processo seletivo, em especial as categorias raciais, sociais e territoriais.

\section{O caráter seletivo e desigual da atuação das agências policiais no Brasil}

Os sistemas penais das sociedades contemporâneas possuem em comum a característica da operacionalidade (ZAFFARONI, 2011, p. 44), ou seja, não possuem capacidade de repreender todas as condutas rotuladas como criminosas. Disso decorre outra característica dos sistemas, que é a seletividade, representando a necessidade de as agências penais realizarem uma seleção das condutas que serão consideradas criminosas e quais serão reprimidas concretamente.

Esses processos de seleção podem ser divididos em duas espécies: a primária e a secundária. Segundo Zaffaroni (2011, p. 43) a criminalização primária decorre do ato de sancionar leis abstratas que determinem, abstratamente, condutas incriminadoras e permitem a 
punição daqueles que as cometem. Por sua vez, a secundária é o exercício concreto da ação punitiva contra as pessoas que supostamente praticaram as condutas abstratamente previstas pela criminalização primária.

Assim, o status criminoso de um comportamento ou de uma pessoa é, na verdade, algo atribuído e não naturalizado (ANDRADE, 2015, p. 266). Essa qualidade é atribuída pelas agências penais, mormente pelas agências policiais, que se encontram em contato mais direto com as ocorrências de delitos. Somente existe crime porque aquele tipo de conduta ou comportamento é visto como criminalizável (BATISTA, 2012, p. 89).

Esses processos são desigualmente distribuídos na sociedade, de modo que recaem com maior frequência nos grupos mais vulneráveis, reforçando o caráter seletivo do sistema e perpetuando uma noção estereotipada e preconceituosa do indivíduo vulnerável com maior tendência ao crime (BARATTA, 2011).

Assim, a criminalização secundária de comportamentos e indivíduos realizada pelas agências policiais tende a procurar a ocorrência de crimes nos estratos sociais e zonas nas quais esta é esperada, nos quais o status criminoso é mais facilmente atribuível aos indivíduos (BARATTA, 2011). Isso ocorre devido a esses agentes se habituarem a selecionar o que é mais simples de encontrar na sociedade e quando são praticados por pessoas que possuem alguma vulnerabilidade (ZAFFARONI, 2011, p. 45).

Lola Aniyar de Castro (2005, p. 162) demonstra que detectou, por meio de seus estudos, que há um tipo de indivíduo ideal para a sociedade - "homem branco, instruído, de profissão liberal e cristão, que, além disso, é amante e respeitador da ordem. A família ideal é composta por pai, mãe, poucos filhos e vive na cidade, geralmente numa casa com quintal ou num apartamento" - e que qualquer pessoa que não se enquadre nessa padronização está mais vulnerável a ser criminalizado.

Segundo os dados do Departamento Penitenciário Nacional - DEPEN (BRASIL, 2018a, p. 31-32), feito em junho de 2017, a população carcerária do país é majoritariamente composta de pessoas negras (pretas e pardas), somando um total de 63,64\% da população do sistema. No tocante às mulheres (BRASIL, 2018b, p. 40) as estatísticas são semelhantes, sendo que as negras representantes de $62 \%$ da população carcerária, sem divisão acerca das pardas. 
Quanto às idades, o Relatório demonstra que a maioria $(29,95 \%)$ é composta por jovens de 18 a 24 anos (BRASIL, 2018a, p. 30), dados que se repetem na população carcerária feminina em 27\% (BRASIL, 2018b, p. 37).

A aferição da escolaridade também reflete a seletividade penal recaindo sobre os mais vulneráveis. Entre os homens, 51,35\% da população carcerária contam com o ensino fundamental incompleto (BRASIL, 2018a, p. 34), dado que se repete com as mulheres na faixa de $45 \%$ (BRASIL, 2018b, p. 43).

Deste modo é possível perceber que a seletividade penal no campo da criminalização secundária no Brasil, vista através das estatísticas do DEPEN, corresponde aos prospectos dos livros e estudos de criminologia crítica, uma vez que demonstram claramente a preferência seletiva por indivíduos vulneráveis, jovens, sem acesso a educação, negros e residentes na periferia.

Desta forma, faz-se necessário destacar que determinadas categorias se mostram presentes com frequência, ganhando centralidade nas estatísticas e que frequentemente são guias da atuação das agências policiais na seleção criminalizante secundária, como a raça, classe e o território, este último pouco explorado e ausente nas estatísticas oficiais.

As categorias supracitadas funcionam, na verdade, como guias para a atividade de seleção. São estas que direcionam o trabalho das agências penais no momento de repreensão a condutas supostamente criminosas. As construções sociais destas vulnerabilidades foram responsáveis por tornar o indivíduo marginalizado como representante perfeito do estereótipo do criminoso.

O estereótipo é a representação social acerca do tipo de indivíduo que pratica crimes. Essa noção direciona a atividade das agências para as condutas mais facilmente detectáveis e cometidas por indivíduos vulneráveis. Deste modo, perpetua as desigualdades, guiando a seleção criminalizante com frequência para repreender pessoas em razão de suas características marginalizadas.

Em suma, a atuação das agências policiais na criminalização secundária atinge, principalmente, grupos vulneráveis, que são aqueles mais em evidência no quadro das desigualdades sociais e no racismo estrutural e assim mais selecionáveis pelo trabalho das agências policiais (SOARES, 2019, p. 36), que costumeiramente age sob filtros sociais, territoriais e raciais (MENA, 2015, p. 25). 
Para os fins do presente trabalho, deseja-se destacar o papel de três categorias de desigualdade que estão frequentemente presentes nas estatísticas dos processos de criminalização secundária: a raça, a classe e o território. As três representam construções sociais que rotularam os indivíduos como excluídos, marginalizados e, principalmente, suspeitos.

A categoria de raça surgiu com mais evidência com o surgimento das teorias raciais no século XIX. Historicamente, a raça negra passou por, pelo menos, três momentos em que foi utilizada pela política criminal para fins de seletividade.

Segundo Evandro Piza Duarte (DUARTE; QUEIROZ; COSTA, 2016, p. 3-5), o primeiro momento foi no período da Criminologia Positivista, responsável pela vinculação das teorias das raças e das teorias da criminalidade, o que contribuiu imensamente para a formação do negro como estereótipo do criminoso, uma vez que rotulou a cor da pele desses indivíduos como um fator criminógeno e que deveria ser combatido.

O segundo momento (DUARTE; QUEIROZ; COSTA, 2016, p. 3-5) já vem na década de 1960, com o paradigma da reação social, é aqui que se deixa de estudar a raça e se passa a estudar o racismo, bem como se identifica que usar a raça como fator de identificação de criminosos é uma das faces desse racismo, inclusive se tornando um dos principais fatores da seletividade penal. "[...] a atuação racista das agências de controle penal tem sido apontada como um elemento fundamental na criminalização da população negra, especialmente dos jovens pobres na periferia" (DUARTE; QUEIROZ; COSTA, 2016, p. 4).

O terceiro momento (DUARTE; QUEIROZ; COSTA, 2016, p. 3-5) trata da existência contraditória, mas simultânea de discursos de desencarceramento e crescimento da população que se encontra sob alguma medida de controle seja de encarceramento ou não. Contudo, foi nesse momento também que se passou a reconhecer os efeitos do colonialismo no discurso criminológico, evidenciando a criminologia como algo construído em favor do imperialismo e que gerou consequências nas realidades pós-coloniais. Aqui é importante ressaltar que, apesar de não haver um discurso abertamente racista, o estereótipo está consolidado e a repressão continua recaindo sobre os mesmos grupos vulneráveis.

Apesar de se ter tornado o racismo mais velado com o passar dos tempos, a prática segue presente e enraizada na cultura que se tem do estereótipo do criminoso, principalmente pela força alcançada no discurso hegemônico no primeiro momento, que se internalizou nos discursos da sociedade e nas suas práticas, tornando-se um racismo estrutural, retirando este 
de um aspecto meramente individual e destacar as relações raciais como relações de poder (ALMEIDA, 2019, p. 46-47).

A questão racial presente no estereótipo do criminoso decorre, em muito, da cultura formada a partir da segregação do negro pós-escravidão e do discurso criminológico positivista que o pôs como uma raça inferiorizada e naturalmente criminosa. Segundo o pensamento de Franz Fanon (2008), a racialização do negro serviu para que este mesmo se compreendesse como inferior e sujeito a padronização de comportamentos do branco como idealizado.

A questão é que o racismo perpassa por todas as instituições, relações sociais e principalmente o sistema criminal e isso reafirma a hierarquia racial de opressões, colocando o negro como um cidadão de segunda classe ou, muitas vezes, nem mesmo um cidadão, gerando um sistema de hierarquização baseado na necessária exploração de um grupo alvo (BORGES, 2018).

Deste modo, é possível depreender que o racismo é inerente ao sistema criminal e, portanto, à seletividade penal. A raça se tornou um critério na escolha daqueles que serão penalizados, tudo decorrente da cultura pós-escravidão que recaiu sobre o negro livre, levando a sua exclusão e extermínio.

\footnotetext{
Este poder sobre corpos negros é exercido em diversas esferas. Seja na total ausência de políticas cidadãs e de direitos, como falta de saneamento básico, saúde integral, empregos dignos; seja pelo caráter simbólico de representação do negro na sociedade como violento, lascivo e agressivo alimentando medo e desconfiança (BORGES, 2018, p. 54, grifo nosso).
}

Em suma, a questão racial é algo indissociável da análise do sistema penal, uma vez que é perceptível que, mesmo com a abolição da escravatura, as práticas e políticas de tratamento das pessoas negras continuam com os traços que já existiam na colonialidade e que mantém essa estrutura na seleção criminalizante secundária.

Esse cenário de negação da cidadania à população negra, decorrente do racismo, teve consequências em diversos outros campos, como das classes sociais e da ocupação dos territórios, uma vez que essas pessoas foram marginalizadas à fragilidade econômica e a residir em lugares sem urbanização e malvistos pelas agências policiais.

Impedidas de acessar a educação, por exemplo, as pessoas negras não tinham condições de assumir trabalhos qualificados que permitissem a melhora de suas situações 
econômicas, perpetuando a permanência destes nos estratos sociais mais baixos e tornando aqueles que conseguem a melhoria como exceções ao padrão social.

Outra consequência desse histórico racista é a ocupação do território, tendo em vista que os processos de urbanização ocorreram de forma desigual e mais ligadas ao interesse econômico do que às necessidades sociais, um processo que Milton Santos chamou de urbanização coorporativa (SANTOS, 2018, p.122).

Portanto, diante desse histórico da formação territorial é certo que esta também reproduziu e manteve as desigualdades raciais e de classe que já existiam, somente as reunindo as outras vulnerabilidades em territórios também considerados marginalizados.

Portanto, o território urbano também se tornou um componente do estereótipo. No momento em que as agências policiais realizam a criminalização secundária selecionando os mais vulneráveis quanto a raça e classe social, estas se direcionam para os locais nos quais essas pessoas estejam concentradas. Explicar-se-á melhor isso conforme a exposição da formação territorial brasileira.

Os territórios na cidade foram dispostos conforme um processo de urbanização tipicamente neoliberal. Em um Estado Neoliberal, os espaços de moradia, bem como a própria questão do espaço urbano, deixam de ser um interesse social do Estado e passaram a ser influenciados pela lógica do mercado, um processo que os urbanistas chamam de financeirização da moradia, configurando um processo no qual aquela deixou de ser considerado de interesse social, para ser considerado de interesse financeiro, sofrendo mercantilização (ROLNIK, 2015, p. 26), que também é exemplificado por Milton Santos (2018, p. 122) em seu conceito de "urbanização coorporativa", já mencionado no presente trabalho.

A consequência é que o espaço de moradia deve ser adquirido pelos seus habitantes, tanto nas áreas mais nobres e caras da cidade, como nas de grande concentração da população de baixa renda. Os territórios periféricos surgiram como consequência à especulação imobiliária, que faz com que os economicamente menos favorecidos precisem se deslocar para lugares em que possam arcar com as condições de moradia (SANTOS, 2018, p. 123).

Em razão das consequências racistas da evolução histórica brasileira, nos estratos sociais economicamente mais baixos se encontram as pessoas negras, vítimas de um estereótipo de inferioridade e de uma violência institucionalizada racista (CARVALHO; DUARTE, 2017, p. 178; SOUZA, 2017, p. 77). 
Os negros também foram vítimas do processo de urbanização desigual, sendo forçados a se recolher em áreas periféricas (VALENTE, 2016, p. 41), tornados o que Jessé Souza (2011, p. 25) configurou como "ralé brasileira". Sendo assim, o território periférico é marcadamente ocupado por pessoas negras e pobres, que foram forçadas pelas desigualdades sociais a se fixarem nesses lugares.

Deste modo, a periferia concentra as pessoas que não se encaixam no indivíduo padrão social identificado nos estudos de Lola Aniyar de Castro (2005, p. 162), portanto, mais facilmente selecionáveis, e que residem no mesmo espaço. Portanto, a periferia concentra, pelo menos, as três categorias de vulnerabilidade: raça, classe e território.

Importante destacar que, inicialmente, o conceito de periferia somente levou em consideração o distanciamento físico de determinada área para o centro da cidade. Contudo, estudos mais recentes demonstram que esse conceito tem sido ampliado para considerar também como periféricos os espaços que possuam condições sociais diversas daquelas encontradas no centro (BORGES, 2004).

A periferização, por si só, já representa uma violência do Estado contra os indivíduos (ALVES, 2018, p. 89), uma vez que não garante igual oportunidade de todos residirem em espaços com níveis adequados de urbanização, fazendo com que as pessoas já marginalizadas sejam deslocadas, segregadas em espaços sem infraestrutura.

No relato de Carolina Maria de Jesus, negra, catadora de papel e residente na extinta favela do Canindé em São Paulo, é perceptível a visão preconceituosa dos agentes policiais acerca do espaço urbano periférico, conforme se vê: “(...) O tenente interessou-se pela educação dos meus filhos. Disse-me que a favela é um ambiente propenso, que as pessoas têm mais possibilidades de delinquir do que tornar-se útil a pátria e ao país” (JESUS, 2018, p. 29).

Ao citar o exemplo do Rio de Janeiro, Marielle Franco (2018, p. 46) afirma que a noção cultural que as pessoas têm é que a favela - e aplica-se esse raciocínio para as áreas periféricas em geral - é uma contraposição ao restante da cidade, como se fosse um território estranho, legitimando a atuação policial diferenciada nesses lugares.

No contexto paraense, em fevereiro de 2019, foi autorizado e divulgado o reforço da Força Nacional de Segurança Pública em sete bairros de Belém para o combate ao crime ${ }^{1}$. Por questões de segurança, não foram divulgados os bairros que receberiam a FNSP. Assim, a

1 Ver em: https://www.diarioonline.com.br/noticias/para/noticia-574373-forca-nacional-vai-atuar-em-setebairros-da-grande-belem.html 
polícia fica responsável pela chamada manutenção da "ordem" nas favelas e periferias (FRANCO, 2018, p. 41).

Deste modo, é possível perceber que a cultura do estereótipo coloca, ao lado do fator econômico e do fator racial, a questão territorial, mesmo que não esteja tão explícita nas estatísticas como as demais categorias. Nessa perspectiva preconceituosa, supostamente seria necessário um policiamento mais rigoroso nesses espaços periféricos para vigiar e controlar os pobres e negros, porque eles seriam os principais criminosos de uma sociedade, seguindo e mantendo os estereótipos percebidos pelas estatísticas.

Isso não significa, em momento algum, que não haja policiamento ou presença das agências policiais nos territórios nobres da cidade. É certo que exista, mas é voltado para proteger aqueles que não pertencem ao estereótipo do que realmente para a garantia da segurança pública (VALENTE, 2014, p. 212).

Por exemplo, um negro em um bairro nobre da cidade certamente não estará lá por residir no bairro, mas por algum outro fator. Isso já abriria uma margem para o uso do território como elemento da seletividade. Segundo Valente (2014, p. 216) "a formação social brasileira criou essa concepção na qual a ‘invasão’ do pobre em um lugar que não é o seu é, em si mesma, uma ameaça".

Assim, a cidade se torna um espaço dividido entre os territórios padronizados e que são ocupados por pessoas que detém privilégios sociais, econômicos e políticos e os territórios compostos pelos integrantes do estereótipo do criminoso: o pobre e, principalmente, o negro. Para Vera Malaguti Batista (2003, p. 108) existem diferentes territórios culturalmente atribuídos a cada classe, que é o que justifica a estranheza dos deslocamentos de uma classe no território da outra.

Isso é bastante perceptível ao se destacar o conceito de território formulado por Milton Santos (2006, p. 39), que afirma que esse é um espaço resultado de uma produção histórica, composto por uma natureza humanizada. Esses espaços na cidade possuem uma cultura própria dos grupos que os ocupam. Júlia Valente (2014, p. 219) faz uma observação acerca das consequências dessa divisão sócio-espacial:

O território é delimitado, construído e desconstruído a partir das relações de poder que se estabelecem no tempo e no espaço e, portanto, a definição de território é política, envolve espaços que mandam e espaços que obedecem, o que é o fundamento de uma geografia da desigualdade. 
O território se relaciona, então, com as categorias raça e classe social uma vez que sua formação é marcada pela segregação das pessoas vulneráveis naqueles espaços menos valorizados, considerados periféricos, perpetuando as desigualdades e a seleção criminalizante dos marginalizados.

Os grupos sociais mais vulneráveis serão também, no quadro maior das desigualdades brasileiras e do racismo estrutural, os mais vulneráveis à escolha dos policiais, porque estes projetarão preconceitos no exercício de sua vigilância. $\mathrm{O}$ elenco escolhido pela vigilância tenderá a ser parecido com os estereótipos destacados no cardápio da cultura corporativa (SOARES, 2019, p. 36).

Conforme os pensamentos do sociólogo camaronês Achille Mbembe, esse cenário de desigualdades e de gestão estatal diferenciada entre classes, raças e territórios acaba por compor uma política de morte, uma política de controle da vida privada e que as rotula como inimigas do bem estar social e as faz morrer, sua chamada necropolítica, que torna o agir violento como uma regra (MBEMBE, 2018, p. 38).

Quando trata sobre a ocupação territorial com origens coloniais, o sociólogo é bastante claro ao destacar como esses espaços foram construídos para reafirmar e perpetuar as relações de poder e a respectiva hierarquização, separando grupos de pessoas e criando diferentes cidadanias pra cada um.

Essa inscrição de novas relações espaciais ("territorialização") foi, enfim, equivalente à produção de fronteiras e hierarquias, zonas e enclaves; a subversão dos regimes de propriedade existentes; a classificação das pessoas de acordo com diferentes categorias; extração de recursos; e. finalmente a produção de uma ampla reserva de imaginários culturais. Esses imaginários deram sentido à instituição de direitos diferentes, para diferentes categorias de pessoas, para fins diferentes no interior de um mesmo espaço; em resumo, o exercício da soberania (MBEMBE, 2018, p. 39).

Deste modo, resta-se demonstrada a seletividade do sistema penal através da atuação desigual das agências policiais na realização dos processos de criminalização, que se guiam pelos estereótipos de criminoso e colaboram com a manutenção destes e das próprias discriminações de raça, classe e território.

\section{O homo sacer e a relação de exceção: a perspectiva de Agamben}


Apesar de ter como pressuposto uma perspectiva branca e eurocêntrica, não se deve negar a importância do pensamento do filósofo italiano Giorgio Agamben para o conhecimento científico da contemporaneidade e como este é capaz de interpretar o contexto que se tem no sistema penal brasileiro.

O objetivo do presente artigo neste ponto é explorar os conceitos apresentados por Agamben no primeiro volume do projeto Homo sacer, delineados de maneira breve e suficiente para formar embasamento teórico a fim de fazer uma leitura pós-colonialista daqueles a partir da realidade dos processos de criminalização secundária demonstrada no tópico anterior.

À luz dos conceitos de homo sacer, relação de exceção, campo e soberania, pretendese encerrar a pesquisa demonstrando a existência desses em uma realidade bastante diferente da qual foram pensados pelo filósofo italiano.

Agamben inicia seus pensamentos a partir da diferenciação das noções gregas para o termo vida. Havia, pois, uma divisão entre as diferenças entre as formas zoé e bíos (AGAMBEN, 2002, p. 9-10). A primeira se referia a vida natural, igualmente tida e vivida por todos os seres vivos, que é exercida em âmbito privativo (oikos) e não tem existência politicamente qualificada.

A segunda forma, a bíos, é a forma qualificada de viver de um indivíduo ou grupo, com existência política e exercida em âmbito público, na pólis. É o que diferencia o ser humano dos outros animais, sendo este o animal político, uma vez que se distingue porque se funda na "politização ligado à linguagem, sobre uma comunidade de bem e de mal, de justo e de injusto, e não simplesmente de prazeroso e doloroso)" (AGAMBEN, 2002, p. 10).

O filósofo parte e dá seguimento aos estudos iniciados por Foucault no livro Vontade de Saber ao afirmar que, na Idade Moderna, a vida natural (zoé) passou a ter interesse político, uma vez que esta foi incluída em mecanismos e relações de poder, fazendo surgir a biopolítica (AGAMBEN, 2002, p. 11), quando mera vida vivente é alvo de interesse e político, caracterizando a Modernidade.

É a partir disso que será forjado o conceito de vida nua, ou seja, aquela vida natural, sem existência política e matável, que caracteriza o homo sacer, sagrado e sacrificável ao mesmo tempo (AGAMBEN, 2002, p. 16). Essa vida nua vai ser o núcleo originário do poder 
soberano através do que se demonstrará ser uma relação de exceção, base da política ocidental.

Para chegar ao conceito de relação de exceção, Agamben retoma a noção aristotélica de homem, na qual este é "um animal vivente e, além disso, capaz de existência política" (AGAMBEN, 2002, p. 15). Segundo o autor, ao colocar a locução "além disso" para definir a possibilidade de vida política do homem, abre-se a possibilidade de que nem todos estes teriam capacidade de existência política.

Portanto, a lógica do biopoder se encontra justamente no fato de uma inclusão da vida nua do homo sacer na esfera política, da zoé na pólis, da transformação do viver em viver bem. Todavia, essa participação, politização da vida nua se dá através da sua exclusão. É através dessa dualidade que o homo sacer se tornará sujeito e objeto do ordenamento político, contudo, sempre pautado na sua relação de inclusão-exclusão.

Em outras palavras, o fenômeno da politização da vida nua, ou seja, da qualificação dessa vida por meio da sua inclusão no campo público (pólis) ocorre pelo Agamben tratou por relação de exceção.

A chamada exceção é uma forma particular de exclusão, na qual algo está fora da norma geral, mas não sem possuir relação com esta, de modo que permanece incluído. É o que Agamben vai afirmar que é uma inclusão por exclusão, haja vista que o que é excluído mantém sua relação com a norma por meio da suspensão desta. "Chamemos de relação de exceção a esta forma extrema da relação que inclui alguma coisa unicamente através de sua exclusão" (AGAMBEN, 2002, p. 26).

A situação, que vem a ser criada na exceção, possui, portanto, este particular, o de não poder ser definida nem como uma situação de fato, nem como uma situação de direito, mas institui entre estas um paradoxal limiar de indiferença. [...] $\mathrm{Na}$ exceção soberana trata-se, na verdade, não tanto de controlar ou neutralizar o excesso, quanto, antes de tudo, de criar e definir o próprio espaço no qual a ordem jurídico-política pode ter valor (AGAMBEN, 2002, p. 26).

Deste modo, a relação de exceção pode ser compreendida como o pertencimento de algo ou alguém em um ordenamento jurídico-social, mas que se encontra incluído por meio da suspensão da ordem jurídica em um campo específico. Como segue uma lógica branca e europeia, Agamben comumente retoma aos exemplos dos Holocausto, no qual as vítimas, em 
especial os judeus, faziam parte da ordem jurídico-social (incluídos), mas somente por meio da sua exclusão dela.

É nessa relação que constantemente se encontra o homo sacer, em sua vida nua, matável, justamente porque não é alvo do viver bem, mas sim apenas do viver, cuja morte não é sofrida pelos demais, sendo até naturalizada, compreendida e esperada.

Mais adiante no desenvolvimento das suas teorias, Agamben passa a descrever o conceito de campo, colocando este como o local central do exercício da biopolítica, no qual se perfaz em excelência a relação de exceção e no qual esta começa a se tornar a regra (AGAMBEN, 2002, p. 175).

Segundo o filósofo o campo é "um pedaço de território que é colocado fora do ordenamento jurídico normal, mas não é, por causa disso, simplesmente um espaço externo" (AGAMBEN, 2002, p. 176). Em suma, é o espaço no qual há a constante suspensão da ordem jurídica, de modo a incluir por exclusão aqueles que se encontram inseridos neste espaço, gerando uma confusão entre vida nua e a norma: “[...] a essência do campo consiste na materialização do estado de exceção e na consequente criação de um espaço em que a vida nua e a norma entram em um limiar de indistinção [...]” (AGAMBEN, 2002, p. 181).

Sendo assim, reunindo alguns conceitos essenciais para a compreensão basilar do pensamento do filósofo italiano, pode-se aplicar, em uma leitura pós-colonialista, a realidade dos processos de criminalização guiados pelos estereótipos da construção social brasileira, conforme se detalhará no tópico seguinte.

\section{A manutenção da relação de exceção e do homo sacer através dos processos de criminalização secundária no Brasil}

A antropóloga Lilia Moritz Schwarcz (2019, p. 24) afirma que desde os primórdios da formação brasileira o que se tem praticado é uma espécie de cidadania incompleta e falha, marcada por vários tipos de violência, como sexismo e o racismo, bem como diversas outras formas de discriminação.

Assim, percebe-se o primeiro indício de possibilidade comparativa da realidade brasileira com o pensamento de Agamben: o fato de que existem pessoas em nosso ordenamento jurídico-social que estão incluídas, mas que são tratadas de formas diferentes. Retoma-se também o que foi afirmado por Mbembe (2018, p. 39): “[...] instituição de direitos 
diferentes, para diferentes categorias de pessoas, para fins diferentes no interior de um mesmo espaço $[\ldots]^{\prime \prime}$.

Deste modo, está-se diante de indivíduos que estão incluídos no ordenamento, mas por meio da sua exclusão, uma vez que não exercem sua cidadania de maneira digna, uma vez que são pessoas marginalizadas em razão das construções econômicas, territoriais e raciais da sociedade brasileira e que, em razão destas vulnerabilidades, são alvos recorrentes da atuação das agências policiais no processo de criminalização secundária.

Os indivíduos já marginalizados pelas suas condições econômicas, territoriais e raciais são atingidos pela distribuição desigual da criminalidade (BARATTA, 2011, p. 161) e, desse modo, representam as vidas nuas, incluídas por exclusão, cujo controle da vida privada mortes são comumente naturalizadas.

Não é desarrazoado o raciocínio comparativo da realidade brasileira com o pensamento agambeniano. Toma-se como exemplo a situação de um jovem negro, residente na periferia e, por óbvio, financeiramente desfavorecido. É um indivíduo que certamente se encontra incluído no ordenamento, uma vez que a Constituição da República (CR/88) garante a igualdade de direitos, mesmo em plano material, mas que na prática esse indivíduo se encontra excluído em diversos aspectos em razão das vulnerabilidades que lhe foram impostas em razão das construções sociais do Brasil.

Além de uma precariedade de direitos e garantias na prática, esse indivíduo também é tratado de maneira diferente por meio dos processos de criminalização secundária que recaem com maior facilidade nele em razão de sua raça, classe social e do território em que reside.

Essas pessoas são as indesejadas pelo padrão idealizado na sociedade brasileira e por isso é concebido como o alvo de controle pelas relações de poder e alvo de uma política que determina, conforme a vida privada dos indivíduos, quem deve viver e quem deve morrer (AGAMBEN, 2002) e que perpetua a figura do homo sacer, criado pela exclusão de determinados grupos a um acesso digno a cidadania.

Diante disso, também é apropriada a relação dos territórios de favela e periféricos com o conceito de campo em Agamben, daí a principal razão para se destacar a seletividade frequentemente operada nesses locais. Se o filósofo determina que o conceito de campo é o local no qual a exceção de torna regra e se tem, em perfeição, a construção da vida, incluída por exclusão, é bastante evidente a comparação com os territórios periféricos. 
Conforme já se demonstrou aqui, a própria noção de território periférico vem da ausência de condições dignas de moradia, que comumente estão presentes nas áreas centrais (BORGES, 2004) e que este concentra indivíduos marginalizados em uma mesma região, facilitando a seletividade penal por meio das agências policiais.

Uma vez que nesses territórios estão segregados indivíduos vulnerabilizados é perceptível que nestes se confirma a noção de campo estabelecida por Agamben, no qual se perfaz com excelência a relação de exceção, de inclusão por exclusão de indivíduos vistos como vidas nuas.

Mesmo quando se trata de territórios nobres e centrais, ainda pode haver a relação de exceção do homo sacer, uma vez que a atuação policial, correspondente à seleção criminalizante, recai nas pessoas que não se enquadram na idealização de cidadão, mas sim no estereótipo de criminoso.

Portanto, as agências policiais exercem um papel fundamental na manutenção dessa relação de exceção com a vida nua no campo (no caso, o território), haja vista que, como sua atuação é guiada pelo estereótipo, esta também é responsável por o reproduzir e o perpetuar.

Deve-se destacar que essas agências não são as responsáveis por decretar as relações de exceção, estas surgem a partir das construções sociais acerca das categorias de raça, classe e território, que ocorreram a partir da marginalização de grupos e indivíduos que não se enquadravam na padronização do ideal de indivíduo.

Conforme o entendimento de Jessé Souza (2017, p. 78), o elitismo brasileiro do grupo hegemônico acabou por transformar a figura do negro, pobre e periférico em inimigo da ordem e que essa perspectiva formada, na verdade, é um meio de justificar o uso da força policial para o exercício do controle e da dominação. "As atuais políticas públicas informais de matar pobres e pretos indiscriminadamente efetuadas por todas as polícias do Brasil, por conta do aval implícito ou explícito das classes médias e altas, têm aqui o seu começo" (SOUZA, 2017, p. 78).

Pode-se perceber que a seletividade penal é o meio de o Estado legitimar a estigmatização do excluído, majoritariamente negro, como perigoso e inferior e também legitimar a perseguição destes pelas viaturas de polícia que possuem "licença para matar pobre e preto" (SOUZA, 2017, p. 83).

As agências policiais não representam a figura do soberano, aquele que é capaz de decretar a relação ou o estado de exceção, que é uma noção que Agamben forma a partir dos 
estudos de Carl Schmitt (AGAMBEN, 2004, p. 11), pois não possuem essa capacidade, mas simbolizam um dos maiores instrumentos para a manutenção dessa relação e desse estado no organismo social.

Portanto, é bastante evidente a presença dos elementos do pensamento agambeniano nas estruturas sociais brasileiras, mesmo que esses tenham sido estudados pelo filósofo a partir de uma realidade bastante diferente do Brasil, a seletividade penal no país representa um contexto no qual se encontram presentes tais conceitos, sendo possível uma análise comparada de uma realidade latino-americana com elementos pensados em um contexto europeu.

Não é demasiado alertar que, apesar da proximidade dos conceitos com o contexto brasileiro, o pensamento de Agamben não é a única forma de interpretação da realidade do sistema penal e sua inerente seletividade, mas sim uma maneira de compreender como a sociedade está estruturada, sendo possível que outras teorias e pensamentos formem uma interpretação diversa da apresentada no presente trabalho.

\section{Considerações finais}

Através de levantamentos bibliográficos e documentais, a pesquisa objetivou e concluiu que há diversas relações que existem entre o pensamento agambeniano e o sistema penal brasileiro, na figura dos processos de seleção criminalizante secundária, que é operacionalizada de forma desigual sobre indivíduos marginalizados.

No primeiro tópico apresentado no desenvolvimento do trabalho, houve a demonstração de como o sistema penal é automaticamente seletivo e que essa seletividade é desigualmente distribuída conforme diversas categorias de vulnerabilidade, principalmente relacionadas a raça, classe social e território.

Ainda nesse tópico, apresentou-se de maneira breve, mas suficiente, as construções sociais que contribuíram para a marginalização de determinados grupos e indivíduos. Demonstrou-se como a construção da categoria racial se deu a partir de uma implementação de um racismo estrutural para inferiorização da população negra e o seu consequente afastamento dos direitos e garantias fundamentais.

Bastante relacionado à construção acerca da categoria raça, e também componente do estereótipo do criminoso, é a questão territorial, uma vez que esta também corresponde a 
uma construção social e que é originada a partir de questões econômicas e raciais, tendo em vista que o processo de urbanização ocorreu mais concentrado em atender necessidades mercadológicas do que sociais.

Desta forma, o território serviu como um local de reunião de indivíduos marginalizados em razão de condições econômicas e raciais, contribuindo para a atuação seletiva das agências policiais, que concentram seus esforços nessas regiões por as considerar criminógenas e com maior necessidade de controle e vigilância.

O desenvolvimento da pesquisa, no objetivo de demonstrar a presença dos elementos agambenianos no processo de criminalização secundária realizado no Brasil, passa a explicar brevemente as noções dispostas pelo filósofo no primeiro livro do seu projeto Homo sacer. Foi feito um levantamento bibliográfico acerca do núcleo dos elementos vida nua, relação de exceção e campo para que estes fossem analisados de maneira comparativa com a realidade brasileira, como se fez no último tópico do desenvolvimento.

Houve, por fim, a demonstração da presença dos elementos escolhidos para o estudo quando se fez a comparação dos conceitos com as construções sociais brasileiras. Primeiramente, como o indivíduo marginalizado sofre um controle maior de sua vida privada e como está incluído no ordenamento, em razão da proteção constitucional, mas que se encontra excluído, ao mesmo tempo, em razão da relação de exceção da qual faz parte.

Ademais, destacou-se a importância do fator territorial tendo em vista a relação deste com o elemento campo, explicado por Agamben a partir de diversos casos relacionados ao contexto europeu. Todavia, essa noção é perfeitamente aplicada no contex to latino-americano, uma vez que a cidade se tornou o campo e, mais especificamente, o território periférico e favelizado, já que nestes se encontram os homo sacer, aqueles incluídos somente por meio da sua exclusão, concretizando a relação de exceção.

Assim, concluiu-se que os conceitos trazidos por Agamben se encaixam em uma leitura pós-colonial através da análise comparada com o contexto brasileiro dos processos de criminalização secundária realizados, mormente, pelas agências policiais, demonstrando que diferentes realidades não estão totalmente apartadas de similitudes, uma vez que ambas podem ser interpretadas por elementos genéricos filosóficos.

\section{REFERÊNCIAS}


AGAMBEN, G. Estado de exceção. 2 ed. São Paulo: Boitempo, 2004

AGAMBEN, G. Homo sacer: o poder soberano e a vida nua I. Belo Horizonte: UFMG, 2002

ALMEIDA, S. L. de. Racismo estrutural. São Paulo: Sueli Carneiro; Pólen, 2019

ALVES, L. de S. Violência e homicídios na cidade de Belém-PA: análise comparativa dos bairros da Batista Campos e Jurunas. In: CHAGAS, C. A. N.; SILVA, M. P. da; VIEIRA, D. C. de M. Geografia da violência: produção do espaço, território e segurança pública. Belém: GAPTA/UFPA, 2018

ANDRADE, V. R. P. de. A Ilusão de Segurança Jurídica: do controle da violência à violência do controle penal. 3 ed. Porto Alegre: Livraria do Advogado, 2015

BARATTA, A. Criminologia crítica e crítica do Direito Penal: introdução à sociologia do Direito Penal. 3 ed. Rio de Janeiro: Revan, 2011

BATISTA, V. M. Introdução crítica à criminologia brasileira. 2 ed. Rio de Janeiro: Revan, 2012

BATISTA, V. M. O medo na cidade do Rio de Janeiro: dois tempos de uma história. Rio de Janeiro: Revan, 2003

BORGES, J. O que é encarceramento em massa? Belo Horizonte: Letramento: Justificando, 2018

BORGES, W. A.; ROCHA, M. M. A compreensão do processo de periferização urbana no Brasil por meio da mobilidade centrada no trabalho. Geografia. Rio Claro, v. 29, n. 3, p. 383-400, set./dez., 2004

BRASIL. Levantamento Nacional de Informações Penitenciárias - Mulheres. INFOPEN. Atualização - Junho de 2017. Departamento Penitenciário Nacional, 2018b

BRASIL. Levantamento Nacional de Informações Penitenciárias. INFOPEN. Atualização - Junho de 2017. Departamento Penitenciário Nacional, 2018a

CARVALHO, S. de; DUARTE, E. P. Criminologia do preconceito: racismo e homofobia nas Ciências Criminais. São Paulo: Saraiva, 2017

CASTRO, L. A. de. Criminologia da libertação. Rio de Janeiro: Revan, 2005

DUARTE, E. P.; QUEIROZ, M. V. L.; COSTA, P. A. A Hipótese Colonial, um diálogo com Michel Foucault: a modernidade e o Atlântico Negro no centro do debate sobre racismo e sistema penal. Revista Universitas JUS, vol. 27, n. 2, 2016, p. 1-31 
FANON, F. Peles negras, máscaras brancas. Salvador: EDUFBA, 2008

FRANCO, M. UPP - A redução da favela a três letras: uma análise da política de segurança pública do estado do Rio de Janeiro. São Paulo: n-1 edições, 2018

JESUS, C. M. de. Quarto de despejo: diário de uma favelada. 10 ed. São Paulo: Ática, 2018

MBEMBE, A. Necropolítica: biopoder, soberania, estado de exceção, política de morte. São Paulo: n-1 edições, 2018

MENA, F. Um modelo violento e ineficaz de polícia. In: KUCINSKI, Bernardo [et al.]. Bala perdida: a violência policial no Brasil e os desafios para sua superação. 1 ed. São Paulo:

Boitempo, 2015, p. 19-26

ROLNIK, R. Guerra dos lugares: a colonização da terra e da moradia na era das finanças. 1 ed. São Paulo: Boitempo, 2015

SANTOS, M. A natureza do espaço: técnica e tempo, razão e emoção. 4 ed São Paulo: Edusp, 2006

SANTOS, M. A urbanização brasileira. 5 ed. São Paulo: Edusp, 2018

SCHWARCZ, L. M. Sobre o autoritarismo brasileiro. São Paulo: Companhia das Letras, 2019

SOARES, L. E. Desmilitarizar: segurança pública e direitos humanos. 1 ed. São Paulo: Boitempo, 2019

SOUZA, J. A elite do atraso: da escravidão à Lava Jato. Rio de Janeiro: Leya, 2017

SOUZA, J. A ralé brasileira: quem é e como vive. Belo Horizonte: UFMG, 2011

VALENTE, J. L. UPPS: observações sobre a gestão militarizada de territórios desiguais. Revista Direito e Práxis, vol. 5, n. 9, 2014, p. 207-225

VALENTE, J. UPPs: governo militarizado e a ideia de pacificação. Rio de Janeiro: Revan, 2016

ZAFFARONI, E. R.; et al. Direito Penal Brasileiro I. 4 ed. Rio de Janeiro: Revan, 2011 